\title{
Gestão Social, Extensão e Teologia da Libertação: uma ANÁLISE A PARTIR DE UM PROJETO JUNTO A COMUNIDADES
}

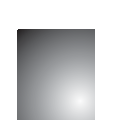

\author{
Social Management, Expansion and Emancipation Theology: \\ one study about research experiences with popular \\ communities
}

Fernando Guilherme Tenório

Professor titular EBAPE/FGV. Rio de Janeiro, RJ. Brasil. E-mail: fernando.tenorio@fgv.br

Thais Soares Kronemberger

Doutoranda do Programa de Pós-Graduação em Ciência, Tecnologia e Inovação em Agropecuária (PPGCTIA) da Universidade

Federal Rural do Rio de Janeiro (UFRRJ).Rio de Janeiro, RJ. Brasil.E-mail: thaisskron@yahoo.com.br

\section{Lais Villela Lavinas}

Pesquisadora Programa de Estudos em Gestão Social (PEGS) da Escola Brasileira de Administração Pública e de Empresas (EBAPE) da Fundação Getúlio Vargas (FGV).Rio de Janeiro, RJ. Brasil.E-mail: lais.lavinas@fgv.br

\section{Resumo}

A gestão social, ao ser compreendida como um processo gerencial dialógico, cuja autoridade decisória é compartilhada entre os participantes da ação, adquire sentido como prática ao ser desenvolvida pela extensão universitária. É inserido nessa temática que o artigo tem como principal objetivo analisar um projeto de extensão dedicado à realização de cursos em gestão social junto a comunidades da Região Metropolitana do Rio de Janeiro. A metodologia adotada compreende a pedagogia emancipatória de Paulo Freire e a filosofia de trabalho em comunidades de Boff, além do método da pesquisa-ação de Thiollent. Dentre os resultados alcançados, destaca-se: a elaboração de projetos comunitários sobre diversas problemáticas; a mobilização $e$ a inserção de representantes de comunidades em instâncias decisórias participativas, como conferências e conselhos municipais; a realização de ações de inclusão digital por meio da implementação de um laboratório de informática; a divulgação e a implementação de cursos em gestão social em uma rede de universidades.

Palavras-chave: Gestão Social. Extensão. Teologia da Libertação.

\section{Abstract}

Social management to be understood as a dialogic process management, in which decision-making authority is shared among the participants of the action makes sense as a practice to be developed by the university extension. It is based on this theme that the article aims to analyze an extension project dedicated to conducting courses in social management with the different communities of the Metropolitan Region of Rio de Janeiro. The methodology includes the emancipatory pedagogy of Paulo Freire's philosophy and work in communities Boff (1986), in addition to the action research Thiollent (1998) method. Among the results achieved stands out: the development of community projects on various issues; mobilization and the inclusion of representatives of communities in participatory decision-making instances and the dissemination of courses in social management within a network of universities.

Keywords: Social Management. Expansion. Emancipation Theology. 


\section{INTRODUÇÃo}

A gestão social é definida como um processo gerencial dialógico entre diferentes sujeitos sociais, na qual a autoridade decisória é compartilhada entre os participantes da ação na busca do bem comum (TENÓRIO, 2012), encontra na extensão universitária o sentido da sua práxis. É por meio do trabalho conjunto com a comunidade, com respeito aos saberes $e$ a autonomia dos sujeitos que prática da gestão social busca identificar, propor e contribuir para a superação da problemática social.

Parte-se do suposto que a concepção da gestão social contém elementos de uma razão ilustrada, ou seja, um conceito que abrange características de uma ação gerencial transformadora, portanto diferenciada daquele em que predomina o caráter subordinante das relações sociais da gestão estratégica, fundada apenas no sucesso, no êxito. (TENÓRIO, 2006, 2012)

Dessa forma, a gestão social promove a inclusão e a interação entre diversos atores, além de encontrar na solidariedade o elemento determinante para o seu desenvolvimento. Ao ser exercida pela ação extensionista, a gestão social soma-se ao caráter participativo preconizado por esta prática, inclusive no plano subjetivo, ao assumir dimensões de crítica, reflexão $e$ emancipação. (THIOLLENT, 2002)

O projeto emancipatório desenvolvido pela extensão busca se concretizar quando os sujeitos conseguem superar obstáculos relacionados à sua condição $e$, desta forma, promover transformações sociais a partir do momento que pessoas mais desfavorecidas têm acesso à educação e, além disso, a construção de conhecimentos novos. (THIOLLENT, 2002)

Este aspecto é trabalhado pela Teologia da Libertação (TL) ao perseguir a constituição de uma consciência de libertação, por meio de uma reflexão crítica sobre o fenômeno da pobreza e da opressão (BOFF, 1980). A libertação não apenas no sentido de superação de uma dependência social, política e/ou econômica, mas na emancipação do sujeito ao longo do processo histórico, orientado para a construção de uma sociedade qualitativamente diferente, justa e igualitária. (GUTIÉRREZ, 2000)

Inserido nesta discussão, o artigo tem como principal objetivo analisar um projeto de extensão dedicado à realização de cursos em gestão social junto a comunidades da Região Metropolitana do RJ pelo referencial da TL, em especial, seus aspectos sobre a conscientização acerca da problemática da realidade e da emancipação do sujeito direcionada pelos valores de liberdade e autonomia. (GUTIERREZ, 2000; BOFF; BOFF, 1979; BOFF, 1980)

Para tal, o artigo encontra-se estruturado em seis seções, incluindo esta introdução $e$ as referências bibliográficas. A segunda seção dedica-se a discutir e analisar a relação entre extensão universitária e gestão social, a partir de seus elementos estruturantes. A seguir, apresenta-se o referencial da TL, com destaque para a discussão sobre a construção de uma consciência crítica e libertadora pelas classes oprimidas. $\mathrm{Na}$ quarta seção descreve-se o projeto de extensão dedicado ao desenvolvimento de cursos em gestão social junto a diferentes comunidades, direcionados para a construção de projetos comunitários, e também para a mobilização e a qualificação da participação da população em espaços decisórios de cogestão com o Estado. E, por fim, são tecidas as considerações finais deste artigo, buscando consolidar os principais aspectos entre o referencial teórico trabalhado $e$ a atividade de extensão analisada.

\section{Extensão Universitária, Gestão SOCial e SUAS Implicações}

A noção de extensão universitária parte do pressuposto que o processo de aprendizagem deve ser baseado no diálogo entre o conhecimento acadêmico e a realidade, em que a construção crítica dos sujeitos passa pelo exercício de aplicar o saber acadêmico levando em consideração o contexto sociocultural.

Partindo-se desse pressuposto a extensão universitária procura criar um intercambio de saberes entre a academia e a população, viabilizando um processo de criticidade entre os atores sociais envolvidos nas atividades.

A história da extensão universitária no Brasil mostra que o conceito já passou por diversas diretrizes conceituais e modos de aplicação prática. A extensão universitária brasileira já se constituiu como curso, serviço prestado às comunidades locais, assistência aos grupos sociais próximos às universidades, já se portou 
como incentivadora da prática cidadã, como uma troca de experiências entre universidade e sociedade e, por fim, se mostrou como a função social das Instituições de Ensino Superior (IES). (RIBEIRO, 2011)

No processo histórico de desenvolvimento do conceito de extensão universitária para além das fronteiras brasileiras é possível encontrar quatro principais momentos de sua aplicação: (i) modelo da transmissão vertical do conhecimento; (ii) ação voluntária sócio-comunitária; (iii) ação sociocomunitária institucional e (iv) acadêmico institucional. Tais momentos se apresentam de forma transitória no interior de cada IES de acordo com a sua história e os seus projetos pedagógicos de ensino. (RIBEIRO, 2011)

Não é propósito deste artigo dissertar sobre cada momento do conceito de extensão universitária e, nem sobre as suas aplicações e diretrizes conceituais ao longo da história do ensino superior. Neste trabalho, a reflexão sobre a noção de extensão universitária está baseada na relação entre a pedagogia emancipatória de Paulo Freire $(1987,2007)$ e no trabalho em comunidades de Clodovis Boff (1986), ligando-se ao conceito de pesquisa-ação de Michel Thiollent (1998, 2002). Ao se miscigenar as reflexões destes autores será possível analisar o objeto de estudo deste artigo, o qual se compreende dentro da extensão universitária, os cursos em gestão social realizados em parceria entre uma entidade da igreja católica e IES localizadas no estado do Rio de Janeiro.

A extensão universitária para Freire (1971) está fortemente baseada na pedagogia crítica, sendo esta calcada no diálogo entre aluno e professor, em que se valoriza uma relação horizontal para que ambos inventem e reinventem juntos o contexto social no qual se encontram inseridos. O diálogo entre educador e educando vem estabelecer uma relação de respeito mútuo, em que o professor reconhece o aprendizado nas experiências de vida de seus alunos, relacionando o saber acadêmico com os saberes populares provindos do contexto sociocultural que vivenciam. A valorização do contexto sociocultural implica atuações educacionais com efeitos mais profundos, em que se questiona o ambiente social, trazendo reflexões críticas para os indivíduos sem transformá-los em parte do meio, e sim, indicando a capacidade que estes possuem de transformarem o contexto.
Através da abordagem de uma pedagogia crítica é possível estruturar relações sociais libertárias entre educadores e educandos, em que se formula uma troca de experiências bilateral, o professor enquanto ensina também aprende.

[...] no processo de aprendizagem, só aprende verdadeiramente aquele que se apropria do aprendido, transformando-o em apreendido, com o que pode, por isso mesmo, reinventá-lo; aquele que é capaz de aplicar o aprendido-apreendido a situações existenciais concretas. Pelo contrário, aquele que é "enchido" por outros de conteúdo cuja inteligência não percebe, de conteúdos que contradizem a própria forma de estar em seu mundo, sem que seja desafiado, não aprende. (FREIRE, 1971, p. 47)

A libertação social do indivíduo é almejada a partir do momento que este se transforma em sujeito de sua realidade histórica, ou seja, adquire consciência social de sua dominação e passa a lutar pela liberdade, opondo-se a alienação e enfrentando às classes dominadoras através do entendimento do seu lugar social, afirmando-o. O desejo por liberdade viria através de relações educacionais que promovessem a formação da visão crítica. (FREIRE, 1987)

Contudo, a educação como prática da liberdade só é possível quando as relações entre educador e educando baseiam-se no diálogo. O conceito de diálogo aponta para uma relação horizontal, em que a convivência mútua entre os atores sociais envolvidos no processo educacional ajuda no entendimento das formas de ser do educando, permitindo ao educador compreender o modo como os seus alunos refletem sobre a estrutura de dominação da sociedade. Questão fundamental para que o professor consiga estimular a reflexão crítica do aluno, colocando em xeque as relações sociais de dominação até então vistas como "naturais". A conscientização do lugar social do indivíduo seria o resultado da ação libertadora de uma educação baseada no diálogo. (FREIRE, 1987)

Toda pessoa que se propõe a realizar o papel de educador deve priorizar a busca pela autonomia crítica de seus educandos, transformando os indivíduos em protagonistas de suas próprias histórias. Educar seria transmitir a noção de aprendizagem aos atores sociais, evidenciar que o pensamento crítico e libertário só é 
possível de ser alcançado quando se assume o papel de eterno aprendiz. (BOFF, 1986)

Essa perspectiva de Boff (1986) associa-se à pedagogia de Freire (2007) sobre a função política da educação. $\mathrm{O}$ ato de educar assume um caráter político a partir do momento em que fornece os caminhos para que os sujeitos sociais transformem as suas realidades. $\mathrm{Na}$ pedagogia freiriana, o educador deve sempre estimular a curiosidade do educando $e$ incentivar à sua insubmissão. O professor deve ensinar o aluno a questionar.

De acordo com os ensinamentos de Freire (1971, 1987) e Boff (1986), é possível pensar que a prática da extensão universitária contribui para o desenvolvimento de um olhar crítico daqueles que aprendem $e$ também dos que ensinam. Porém, para que este fato ocorra é necessário que se estabeleça uma relação de igualdade entre educadores e educandos, em que o educador se aproxime da realidade vivenciada pelos educandos. É preciso que o educador formule suas ações e suas práticas baseando-se no contexto sociocultural de seus alunos, ou seja, é importante que o professor estabeleça um contato participante com o meio sociocultural da população para a qual ensina.

Boff (1986) defende a ideia de que a inserção real do educador no contexto sociocultural do educando vem evitar que a prática pedagógica se de apenas pelo viés autoritário, em que ocorre o prevalecimento do educador nas relações de ensino-aprendizagem. $\mathrm{O}$ professor ao se inserir na realidade sociocultural de seus alunos provocaria uma reestruturação do seu papel de agente dominador por assumir o papel de aprendiz ao valorizar as experiências práticas vivenciadas por seus alunos e, não apenas o conhecimento teórico disseminado pelas universidades.

A igualdade entre os atores sociais envolvidos na prática educacional facilita a troca de informações e experiências, instigando a visão crítica. O objetivo fundamental da prática da extensão universitária seria possibilitar "[...] a problematização do homem-mundo ou do homem em suas relações com o mundo e com os homens, possibilitar que estes aprofundem sua tomada de consciência da realidade na qual e com a qual estão". (FREIRE, 1987, p. 33)

É possível pensar que o conceito de extensão universitária difundida por Freire $(1971 ; 2007)$ e Boff (1986) se conecta com a ideia de pesquisa-ação apresentada por Thiollent (1998). Esta última parte do pressuposto de que os sujeitos que se envolvem em ações educativas que unam a difusão $e$ a produção de conhecimento compõem um grupo com objetivos e metas comuns, interessados em um problema que emerge num dado contexto no qual atuam, misturando os papéis entre educador e educando. O papel do professor consiste em ajudar o grupo de alunos a problematizar, ou seja, situá-los em um contexto sociocultural mais amplo, para assim possibilitar a ampliação da consciência dos atores sociais envolvidos no processo educacional, tendo como objetivo apontar formas de transformação das ações dos sujeitos e das práticas institucionais. (THIOLLENT, 1998)

Ao mesmo tempo em que a extensão universitária proporciona o desenvolvimento do olhar crítico dos indivíduos e transforma o educando em agente ativo, alterando o seu modo de se relacionar com o mundo em que está inserido, ela é de fundamental importância para que o educador tome consciência do espaço social em que transita e vive, permitindo a abertura de um diálogo igualitário e respeitoso como método pedagógico.

Nesse sentido, a noção de extensão universitária guarda relação direta com o conceito de gestão social, pois esta é compreendida como uma prática inclusiva, plural e igualitária baseada em uma relação dialógica entre diversos atores, em que ocorre um compartilhamento de visões, interesses e ações na busca do bem comum (TENÓRIO, 2006, 2009).

A gestão social é definida como "[...] uma gestão ampliada na qual o processo decisório seria vinculante ao diálogo consciente, procedimental, por meios dos diferentes atores da sociedade, sob a perspectiva de sujeito em ação" (TENÓRIO, 2009, p. 2). Observa-se que o conceito de gestão social possui características em comum com o de extensão universitária ao colocar o diálogo consciente e horizontal como chave para que os atores sociais em conjunto desenvolvam alternativas que beneficiem o coletivo.

Importante ressaltar que o processo dialógico na prática da gestão social só se fundamenta se todos os participantes da ação social admitem sua validade, ou seja, a verdade é um acordo alcançado por meio da discussão crítica, da apreciação intersubjetiva. Sob a atuação da ação comunicativa, nesse tipo de ação o indivíduo busca motivar o outro para que esse concor- 
de com o seu argumento, sendo a linguagem utilizada como fonte de integração social. (TENÓRIO, 2008)

O fato de apresentar os indivíduos como sujeitos ativos e, que são capazes de estabelecer uma produtiva troca de informações entre si faz com que a gestão social se estabeleça como uma interessante proposta para se pensar em uma estrutura prática-pedagógica no exercício da extensão universitária, em que o espaço seja visto como um local de troca de conhecimento, ampliação do pensamento crítico e de aprendizagem social.

Além disso, a relação entre gestão social e extensão universitária requer a busca de um ideal emancipatório que seja direcionada por valores de liberdade e autonomia do indivíduo, bem como da criticidade dos assuntos e das problemáticas abordadas. É por meio do diálogo sem coação, da inclusão e da participação de todos os atores na decisão compartilhada, que a prática da extensão é desenvolvida, a fim de contribuir para a transformação social, política e cultural da sociedade.

\section{Teologia da Libertação: do REFERENCIAL À PRÁXIS}

A TL teve origem na igreja latino-americana na década de 1960, em um período marcado por profundas transformações de ordem social e política, com destaque para as mobilizações populares que reivindicavam mudanças na estrutura socioeconômica dos países latino-americanos. Tais transformações podem ser explicadas pela (i) industrialização impulsionada pelos capitais multinacionais que provocou o agravamento da dependência dos países periféricos e aprofundou as contradições sociais, como também pela (ii) abertura nos países latino-americanos do surgimento dos movimentos de guerrilha, golpes de Estado militares e crise de legitimidade do sistema político. (LÖWY, 1938; BOFF; BOFF, 2001)

A formação da TL não surge no interior da cúpula da Igreja, mas da periferia para o centro. Ou seja, os setores sociais no campo religioso que irão influenciar a constituição dessa teologia são todos periféricos, marginais em relação à instituição. Como exemplo, têm-se os movimentos católicos leigos, compostos pela Juventude Universitária Católica (JUC), Juventude Operária Católica, Ação Católica, movimentos de educação de base no Brasil ou de promoção agrária na Nicarágua, Federações dos Camponeses Cristãos em El Salvador e, principalmente, comunidades de base. (LÖWY, 1938)

Contudo, é na II Conferência Geral do Episcopado Latino-americano (CELAM) em Medellín, Colômbia, realizada em 1968, que novas resoluções são adotadas, não apenas com denúncias sobre as estruturas existentes fundadas na injustiça e na violação dos direitos fundamentais da população, mas também com a expressão revolucionária da libertação de toda a opressão. (LÖWY, 1938; BOFF, 1980)

O método oficializado em Medellín, no qual se constrói a TL, segue a seguinte estrutura: análise da realidade - reflexão teológica - ação pastoral, o que constitui uma verdadeira transformação na forma de praticar teologia. Simplesmente não parte de quadros elaborados de forma abstrata, mas de uma leitura baseada na realidade, na qual se processa a práxis da fé. De forma geral, a adoção desse método significa que o sentido principal da TL é a libertação histórica dos pobres e oprimidos. "Libertação, como a própria semântica sugere, constitui-se como uma ação criadora da liber-dade. É uma palavra-processo, palavra-ação, intencionalmente orientada a uma práxis que liberta de e para". (BOFF, 1980, p. 18)

A ideia da libertação explica-se pelo cenário de pobreza dos países latino-americanos interpretada pelo "[..] preço a ser pago para que o Primeiro Mundo possa desfrutar da abundância" (BOFF \& BOFF, 2001, p. 108). As causas da pobreza na TL são compreendidas pelo referencial marxista, sendo encarado como a explicação mais coerente e universal para este cenário de contradições do sistema capitalista e de luta de classes, bem como considerado como a única proposição radical para a extinção das formas de opressão. (LÖWY, 1938)

A libertação ocorrerá quando o oprimido passa a ser percebido como sujeito político, sendo alcançada por meio de um processo de conscientização das desigualdades sociais, culturais, políticas e econômicas que caracterizam a sociedade. (LÖWY, 1938; BOFF, 1980)

Nos segmentos eclesiais esta interpretação agiu como "um sal e um fermento" (BOFF; BOFF, 2001, p. 108) para as ações das pastorais sociais. Daí, as bases para a TL estarem constituídas em um processo de ruptura e libertação frente à situação de dependência 
em que se encontravam os países periféricos em relação aos países centrais.

Contudo, torna-se importante ressaltar que as condições concretas para o surgimento da TL só foram dadas pela atuação militante dos movimentos populares e grupos cristãos em direção a uma libertação sociopolítica, entendida como uma libertação completa e integral. (BOFF; BOFF, 2001)

Esse aspecto é o que diferencia a TL, ou seja, sua relação orgânica com a prática pastoral dos agentes, como a teoria de sua ação (BOFF; BOFF, 2001), ao contrário de uma teologia pautada em uma ideologia racionalizadora e justificadora de uma determinada ordem social (GUTIÉRREZ, 2000). O teólogo da libertação não está representado por um intelectual de gabinete, mas em um "intelectual orgânico", um "teólogo militante" que ajuda as classes oprimidas a tomar consciência da problemática da realidade (BOFF, 1980). "Ele conserva certamente um pé num centro de reflexão e outro na vida da comunidade. Aqui, aliás, assenta seu pé direito". (BOFF; BOFF, 2001, p. 38)

Nesse sentido, a TL estabelece o comprometimento com os oprimidos e age por meio da reflexão crítica, da tomada de consciência do sujeito sobre o contexto histórico de dominação, de marginalização e de pobreza generalizada que marca a América Latina. Ao surgir de uma práxis experimentada ou de uma experiência praticada em tal contexto, a TL busca pelo par ação-reflexão alcançar uma práxis mais esclarecida e qualificada, que seja caracterizada como libertadora. (BOFF, 1980)

Persegue-se, dessa forma, um comportamento cada vez mais consciente do sujeito ativo no processo histórico, ou seja, consciente da injustiça social e de todo elemento repressivo que o impeça de participar da mudança das estruturas sociais e da gestão política. Esta libertação ultrapassa a dependência econômica, social e política, consistindo em um processo de emancipação do indivíduo ao longo da história, libertando-se de todo tipo de opressão e tornando-se sujeito artífice do próprio destino. (GUTIÉRREZ, 2000; BOFF, 1980)

Nesse sentido, a TL ao conceber a história como um processo de libertação humana, percebe a liberdade como uma conquista histórica e compreende a passagem de uma liberdade abstrata para uma liberdade real que não se realiza sem luta contra todo o tipo de opressão humana. Isso implica mais do que melhores condições de vida e transformação de estruturas sociais, políticas e econômicas, significa a construção contínua de novos sujeitos, ou seja, uma revolução cultural permanente. (GUTIÉRREZ, 2000)

Propugnar tal revolução significa construir uma sociedade justa, fraterna e igualitária, baseada em novas relações de produção e na supressão de todas as formas de submissão entre países, classes e sujeitos. Contudo, para que isso ocorra é necessário que a libertação seja assumida pelo povo oprimido e, para isso, deverá partir dos seus próprios valores. (BOFF, 1980)

Essa perspectiva guarda relação direta com a pedagogia emancipatória de Paulo Freire (1987) que a partir de uma ação cultural realizada pela união entre teoria e práxis, desenvolve um trabalho de conscientização dos oprimidos. Este trabalho é caracterizado pela percepção dos oprimidos da sua própria situação para um processo de transformação da sua relação com o mundo e com os demais. Dessa maneira, ocorre a passagem de uma "consciência ingênua" que não problematiza e não percebe as contradições da realidade, para uma "consciência crítica" que reconhece as categorias opressoras e se permite ao diálogo crítico e a criatividade. (GUTIÉRREZ, 2000; BOFF, 1980)

Assim, de acordo com Freire (1980), um dos propósitos da extensão é desenvolver a conscientização crítica por meio do diálogo, do respeito aos saberes e da autonomia dos sujeitos. "O que temos de fazer, na verdade, é propor ao povo, através de certas contradições básicas, sua situação existencial, concreta, presente, como problema que, por sua vez, o desafia e, assim, lhe exige resposta, não só no risível intelectual, mas no nível da ação". (FREIRE, 1987, p. 49)

\section{Gestão Social na Extensão UNIVERSITÁRIA}

Esta seção dedica-se a apresentar e analisar uma prática de extensão realizada há 23 anos no âmbito de um programa de pesquisa de uma IES dedicado à temática da gestão social. A prática a ser analisada refere-se ao desenvolvimento de cursos em gestão social junto a comunidades da Região Metropolitana do Rio de Janeiro. O primeiro deles é direcionado para a elaboração, administração e avaliação de projetos 
comunitários desenvolvidos com moradores de diferentes comunidades em diversas áreas e problemáticas. Em relação ao segundo curso, objetiva-se mobilizar e qualificar a participação da população em instâncias decisórias de cogestão com o Estado, como os conselhos e as conferencias de políticas públicas.

Tais atividades são implementadas tradicionalmente em parceria com uma entidade da igreja católica e, mais recentemente, com duas IES sediadas em localidades do interior do estado do Rio de Janeiro. A parceria com a instituição religiosa justifica-se pela sua inserção por meio de ações assistenciais e sociais junto às comunidades localizadas em zonas urbanas mais vulnerabilizadas economicamente. Em relação às IES, o trabalho em conjunto surgiu da motivação em ampliar e interiorizar a implementação dos cursos em gestão social.

O método adotado para o desenvolvimento de ambos os cursos compreende o processo ensino-aprendizagem, estruturado sob a perspectiva da relação teoria-prática, fundamentado na educação dialógica e no respeito aos saberes existentes no grupo. Baseia-se na pedagogia emancipatória de Paulo Freire (1987; 2007) e na filosofia de trabalho com comunidades de Clodovis Boff (1986), bem como no conceito de pesquisa-ação de Michel Thiollent (1998), no qual os discentes e pesquisadores têm um envolvimento orgânico e uma relação intersubjetiva com os sujeitos integrantes do processo. "Com a pesquisa-ação os pesquisadores pretendem desempenhar um papel ativo na própria realidade dos fatos observados". (THIOLLENT, 1998, p. 16)

Sobre esse aspecto, a equipe envolvida na condução dos cursos em gestão social possui uma formação interdisciplinar (Administração, Ciências Sociais, Economia, Engenharia, História) e é composta por docentes e discentes de graduação e pós-graduação (cursos de Mestrado e Doutorado). A elaboração e a condução das atividades realizam-se por meio de um trabalho conjunto fundamentado na prática dialógica, em aspectos inclusivos e plurais entre os diversos integrantes da equipe, atuando, desta forma, sob as bases da gestão social.

Esta é definida como o processo gerencial dialógico no qual a autoridade decisória é compartilhada entre os diferentes participantes da ação em qualquer sistema social. "O adjetivo social qualificando o subs- tantivo gestão é visto como o espaço privilegiado de relações sociais no qual todos têm direito à fala, sem nenhum tipo de coação". (TENÓRIO, 2008b, p. 158)

O conceito de gestão social encontra fundamento na teoria da ação comunicativa de Jürgen Habermas, pois é entendida como um processo dialógico, no qual todos os participantes da ação admitem sua validade, ou seja, a verdade é um acordo alcançado por meio da discussão crítica, da apreciação intersubjetiva. Sob a atuação da ação comunicativa, nesse tipo de ação o indivíduo busca motivar o outro para que esse concorde com o seu argumento, sendo a linguagem utilizada como fonte de integração social. (TENÓRIO, 2008b; TENÓRIO, 2012)

Ao adotar a gestão social como eixo norteador das atividades de extensão promove-se o fortalecimento do diálogo, da participação e da inclusão na relação entre comunidade e universidade. Como ressaltado por Boff (1986), as relações dialógicas só ganham sentido quando ocorrem na prática, da práxis falada $e$ refletida. É provocar e fomentar o processo de reflexão conjunto entre os discentes, docentes e os membros da comunidade a partir das experiências vivenciadas por cada indivíduo.

Na prática extensionista, o trabalho coletivo entre agentes e comunidade persegue a autonomia do processo educativo, entendida como autodeterminação ou autodireção, na qual segue um caminho duplo: consiste no encontro recíproco do saber do agente com o saber da comunidade. O meio para que isso aconteça é o diálogo, a cooperação entre os envolvidos. "É só no intercâmbio de saberes que o processo educativo se desenvolve, seja do lado do agente como do lado do povo". (BOFF, 1986, p. 30)

Sobre as atividades de extensão aqui analisadas, os cursos em gestão social são realizados semestralmente e possuem carga horária total de 45 horas. Seu desenvolvimento está relacionado a disciplinas sobre a temática da gestão social oferecidas em cursos de pós-graduação (Mestrado e Doutorado) em Administração de uma IES do município do Rio de Janeiro. Por meio da participação nessas disciplinas, os alunos de pós-graduação adquirem contato com a base teórica neste campo de estudo e envolvem-se em projetos de extensão universitária. Busca-se, desta forma, trabalhar a gestão social não apenas nos eixos ensino e pesquisa, mas também pela ação extensionista, fomentando 
uma relação ensino-aprendizagem direcionada para a conjunção teoria-prática.

Ambos os cursos são realizados no âmbito de um laboratório de informática estruturado com o objetivo de apoiar a realização dos cursos em gestão social e fortalecer com o uso de tecnologias digitais a relação entre o conhecimento universitário e a experiência social concreta. Disponibilizar o acesso à internet $e$ às ferramentas de trabalho computacionais para os moradores de comunidades de baixa renda amplia os canais de acesso à informação, assim como o conhecimento sobre mecanismos e ferramentas tecnológicos, a fim de auxiliarem na construção de resoluções e alternativas para os conflitos e os problemas enfrentados no cotidiano.

No caso do curso dedicado a gestão de projetos comunitários, sua realização data desde 1990 e compreende três módulos: (i) elaboração; (ii) administração e (iii) avaliação de projetos. Tem-se como principal objetivo trabalhar ferramentas e tecnologias sociais direcionadas para a construção, gestão e avaliação de projetos, sendo estes pensados de forma coletiva $e$ dialógica com a comunidade. Entende-se por tecnologia social todo conhecimento que, produzido no meio acadêmico, possa ser útil a processos que envolvam a participação cidadã. Esta última é compreendida como todo método que contribua para processos democráticos de decisão. (TENÓRIO, 2008c)

O público compreende moradores de diferentes comunidades do município do Rio de Janeiro, assistidas pelas pastorais vinculadas à entidade da igreja católica parceira da iniciativa. Tais comunidades estão localizadas especialmente na Zona Norte e Zona Oeste, consideradas como áreas mais vulneráveis do ponto de vista social e econômico.

Em relação ao material didático adotado no curso, foi elaborado de forma conjunta entre docentes, discentes de mestrado e de doutorado em Administração especialmente para esta atividade extensionista, em um processo participativo junto aos alunos do curso.

O primeiro módulo, elaboração, é dedicado aos aspectos teórico-metodológicos considerados como iniciais no processo de construção de um projeto, sendo apresentados em quatro etapas, a saber: (i) identificação; (ii) viabilidade; (iii) elaboração e (iv) análise. A identificação consiste em mapear o que será realizado no projeto, ou seja, a organizar e reunir dados e informações sobre a proposta que se quer desenvolver. Já a segundo etapa, viabilidade, ensina aos alunos estudarem os dados e informações coletadas para que compreendam as possibilidades de execução de seus projetos, incentivando à reflexão de alternativas aos problemas que prejudicam a viabilização de seus projetos. A terceira etapa consiste, entre outros aspectos, o ensino metodológico de programação da implementação do projeto, planejando a distribuição das atividades e dos recursos. A quarta e última etapa consiste na análise caracterizada como o momento em que os participantes do curso aprendem a fazer um estudo crítico sobre a relevância de seus projetos, verificando se suas propostas ainda são pertinentes ou se necessitam de reformulações.

O segundo módulo do curso, administração, volta-se para dois objetivos fundamentais: a conscientização da continuidade da participação e o gerenciamento dos recursos conquistados pela aprovação dos projetos comunitários. O intuito de esse módulo ser pensado por esses objetivos é explicado pela observação ao longo das edições do curso, em relação a desmotivação dos integrantes após a implementação do projeto. As causas que geram esta desmotivação são inúmeras, porém a mais apontada seria a dificuldade em compreender que a atuação dos participantes nos projetos não podem se limitar à sua fase de implementação. É necessário conscientizar os envolvidos que um projeto comunitário é um trabalho coletivo e que a participação de todos é o elemento-chave para ele ser bem-sucedido. Ao mesmo tempo, que este módulo trabalha a importância da participação, apresenta as funções básicas necessárias para se administrar os recursos (financeiros, humanos e materiais) de um projeto comunitário em fase de execução.

Finalmente, o terceiro módulo é direcionado para o ensinamento dos instrumentos de avaliação de projetos. Nesta fase os participantes do curso aprendem métodos de avaliação para poderem efetivar um balanço analítico prático, buscando o planejamento correto de recursos, assegurando o desenvolvimento integral do projeto. Além desse conteúdo, o material didático também visa a demonstrar as maneiras como as agencias financiadoras analisam e avaliam projetos em vista de concessão de financiamento. Essa segunda parte do módulo tem o intuito de familiarizar os participantes do curso com aspectos burocráticos e metodológicos das agências de financiamento. 
Ao final do curso, os projetos construídos pelos alunos refletem as problemáticas das suas comunidades em diversas áreas, em especial educação, saúde, segurança alimentar e nutricional, geração de emprego e renda, cultura e meio ambiente. A construção dos projetos ocorre por meio de um trabalho conjunto, que envolve a troca de saberes e de experiências entre docentes e discentes com os representantes comunitários. Busca-se seguir a proposta pedagógica freiriana caracterizada como um processo democrático, transformador e emancipatório desenvolvido por meio do diálogo e do respeito à cultura local. (SERRANO, 2011)

Ao total, cerca de 100 discentes dos cursos de pós-graduação em Administração e Administração Pública já atuaram nesta atividade de extensão, além de contar com a participação de mais de 1200 moradores de diversas comunidades da Região Metropolitana do estado, sobretudo dos municípios do Rio de Janeiro, Niterói, São Gonçalo, Seropédica e Itaguaí.

Em relação ao curso dedicado à temática da gestão social em conselhos municipais, possui um período de realização mais recente, desde 2010, quando comparado ao curso de projetos comunitários e pode ser caracterizada como uma ação sistematizada, mas em constante adaptação e reformulação de si mesma.

O objetivo central é mobilizar e qualificar a participação da população para sua inserção em espaços institucionais de cogestão com o Estado, como os conselhos municipais de políticas públicas, visando aumentar o potencial democrático e participativo destas instâncias. Desenvolvido no âmbito da extensão universitária, o projeto pedagógico vislumbra integrar a experiência acadêmica dos educadores com a experiência da participação cidadã vivenciada pelos alunos em seus cotidianos.

Importante ressaltar que o fortalecimento de arranjos institucionais de participação constitui uma das metas do Plano Brasil $2022^{1}$, conduzido no âmbito da Secretaria de Assuntos Estratégicos (SAE) da Presidência da República: "Institucionalizar o Sistema Nacional de Participação Social e fortalecer os mecanismos de participação já existentes, em especial os Conselhos de Políticas Públicas, as Conferências Nacionais e as Ouvidorias" (BRASIL, 2010, p. 156). O alcance de tal meta ocorrerá por meio de ações que busquem assegurar a participação da sociedade nos processos de elaboração, implementação e avaliação das políticas públicas, bem como promover ampla publicidade dos conselhos, com a divulgação de suas reuniões, pautas, atas e deliberações. (BRASIL, 2010, p. 156)

O curso é direcionado para moradores de diferentes comunidades do estado do Rio de Janeiro, em especial, membros de movimentos sociais, agentes de pastorais e/ou conselheiros municipais, devido à atuação e engajamento social e político destes atores em suas entidades representativas. Cerca de 120 moradores residentes de municípios como Rio de Janeiro, Itaguaí, São Gonçalo, Volta Redonda, Seropédica e Niterói já participaram deste projeto.

Como atividade de extensão, o curso proporciona o envolvimento de alunos de graduação e pós-graduação (Mestrado e Doutorado), como também de docentes e pesquisadores. Ao total, 25 alunos de diferentes formações História, Ciências Sociais, Economia, sobretudo em Administração e Administração Pública, atuaram como agentes de extensão no âmbito desta atividade.

A ementa pedagógica do curso está estruturada entre aulas teóricas e práticas, alternando-as, ou seja, para cada aula teórica existe uma aula prática. As primeiras são caracterizadas pela apresentação, debate e apreensão do conteúdo em sete temáticas, a saber: (i) gestão social, participação e cidadania; (ii) papel da burocracia e trajetória das políticas sociais; (iii) dinâmica política dos atores sociais; (iv) Constituição Federal de 1988 e participação cidadã; (v) conselhos municipais de políticas públicas; (vi) conselheiros municipais; e por último, (vi) práticas de conselhos municipais. Já as aulas práticas são pensadas para que os moradores exponham os seus conhecimentos e suas realidades socioculturais dialogando com o conteúdo trabalhado na parte teórica. Durante as aulas práticas os moradores apontam as dificuldades de suas experiências no âmbito da participação cidadã e, propõem junto aos agentes de extensão (discentes e docentes) as problemáticas apresentadas. O principal objetivo das aulas práticas seria proporcionar um diálogo horizontal entre a esfera acadêmica e o conhecimento prático adquirido através da vivência cotidiana.

Assim como no curso dedicado a temática de projetos comunitários, o material didático também foi construído a partir da perspectiva coletiva, num processo dialógico e interativo, que contou com o envolvimento de representantes de comunidades que 
participaram deste projeto de extensão, a partir da leitura e do debate sobre as problemáticas da realidade que envolvem a relação Sociedade-Estado.

Ao final do curso, após o desenvolvimento de uma prática pedagógica direcionada para a conscientização da importância do envolvimento da população em espaços públicos institucionais junto ao Estado, ocorre a participação pelos alunos em reuniões ordinárias dos conselhos de políticas públicas de diversas áreas do município do Rio de Janeiro - saúde, educação, assistência social, direitos da criança e do adolescente, cultura, política urbana - a fim de relacionarem o conhecimento adquirido com a prática de funcionamento destes arranjos institucionais.

A conciliação entre conteúdo prático e teórico seria a chave do estímulo para a problematização da realidade cotidiana vivenciada pelos representantes de diferentes comunidades envolvidos no curso. A complementaridade gerada pelas informações apresentadas nas experiências educacionais de cunho prático-teóricas desenvolvidas no curso dedicado aos conselhos municipais permite que os participantes mapeiem com maior clareza o seu lugar social no processo histórico, descobrindo-se como agentes capazes de interferirem em suas realidades. O diálogo horizontal proporcionado pelo exercício de ligação entre ação e teoria descortina estruturas socioculturais e políticas, proporcionando à reflexão sobre os comportamentos culturais, problematizando relações sociais dominadoras e abrindo a possibilidade da libertação individual através da construção de um olhar crítico.

Como resultados destas atividades de extensão desenvolvidas por meio da realização de cursos em gestão social, dedicados às temáticas de projetos comunitários e conselhos municipais, pode-se destacar:

a) Inserção do conceito de gestão social em atividades de extensão universitária ao promover o aprendizado $e$ a atuação de discentes de graduação e pós-graduação, sobretudo em cursos de Administração e Administração Pública, em uma gestão dialógica e transformadora aliada a uma prática pedagógica que persegue valores de liberdade e autonomia na troca de experiências e saberes entre universidade $e$ comunidade.

b) Contribuição para a inclusão digital de moradores de comunidades de baixa renda que por meio da implementação de um laboratório de informática tornou-se possível o desenvolvimento de conteúdos e o aprendizado em conhecimentos básicos computacionais.

c) Construção de projetos comunitários sobre diferentes problemáticas - segurança alimentar e nutricional, saúde, educação, geração de emprego e renda, cultura, meio ambiente - que afetam o cotidiano de diferentes comunidades localizadas na Região Metropolitana do Rio de Janeiro.

d) Mobilização e inserção de representantes de comunidades em arranjos institucionais de participação como membros de conferências nacionais e conselhos municipais do Rio de Janeiro, a saber: $3^{\text {a }}$ Conferência Nacional dos Direitos de Pessoa com Deficiência; $1^{\text {a }}$ Conferência Nacional sobre Transparência e Controle Social (Consocial), organizada pela Controladoria Geral da União (CGU); Conselho Municipal de Cultura; Conselho Municipal do Artesanato. No caso deste último, sua constituição foi impulsionada por um representante da associação de artesãos do Rio de Janeiro, que, após participar do curso e obter contato com o conteúdo e a prática dos conselhos municipais, se sentiu motivado a exercer a função de conselheiro em sua área de atuação.

e) Capacitação de representantes da sociedade que atuam como conselheiros municipais de políticas públicas do estado do Rio de Janeiro, especialmente nas áreas de saúde, assistência social, idoso e direitos da pessoa com deficiência. Ressalta-se que, no caso do Conselho Municipal de Direitos da Pessoa com Deficiência do Município de São Gonçalo-RJ, após adquirir conhecimento sobre sua dinâmica de funcionamento e o exercício da função de conselheiro, um aluno que já atuava como membro deste espaço tornou-se presidente do conselho.

f) Difusão na implementação de cursos em gestão social por meio do estabelecimento de parcerias com IES, sediadas em municípios do interior do estado do Rio de Janeiro, com a finalidade de ampliar e interiorizar esta atividade de extensão. Além da parceria com instituições de ensino, o curso conta com o apoio de órgãos públicos federais na realização de palestras $e$ na distribuição de materiais didáticos sobre a temática da transparência pública e do con- 
trole social, com o propósito de fortalecer a capacitação e promover maior publicização junto à comunidade sobre a importância da participação em conselhos municipais.

\section{Considerações Finais}

Buscou-se neste artigo apresentar a experiência de um projeto de extensão dedicado à realização de cursos em gestão social sobre projetos comunitários e participação em conselhos municipais, baseado no diálogo horizontal como método pedagógico. Ao colocar o diálogo como principal ferramenta pedagógica permite-se a construção de um conhecimento compartilhado que relaciona teoria e prática, aproximando as realidades dos diferentes atores sociais envolvidos no processo educacional proposto pela atividade de extensão analisada.

O conhecimento compartilhado gerado nos cursos descritos no tópico anterior baseia-se em uma pedagogia de conscientização acerca da problemática da realidade e, como consequência, de emancipação individual frente à estrutura sociocultural e política historicamente dominadora. As atividades de extensão também se encontram fundamentadas no referencial de libertação do sujeito de estigmas sociais e culturais por meio da compreensão do seu lugar social no contínuo processo histórico de (re)constituição da sociedade em que está inserido.

Sob o referencial da TL é possível afirmar que os cursos em gestão social constituem práticas de extensão universitária que perseguem uma práxis pedagógica que preze pela educação da autonomia e da libertação opressora, ou seja, que não buscam apenas transmitir conhecimento, mas sim, fornecer instrumentos para que o conhecimento seja construído pelo próprio sujeito, colocando-o em uma posição ativa frente ao seu lugar social, tornando-o protagonista de sua própria história.

Portanto, pode-se dizer que os cursos analisados estão inseridos em um método que persegue as transformações de cunho estrutural ao buscar novos posicionamentos culturais do sujeito social, contribuindo para a formação de um pensamento que problematize a perpetuação de relações sociais opressoras. A atividade de extensão estudada colabora para que os atores sociais envolvidos alcancem a autonomia e transformem suas realidades cotidianas de forma a construir relações libertárias em seus meios sociais, oprimindo mecanismos socioculturais de dominação que garantem a posição social privilegiada de determinados grupos.

\section{REFERÊNCIAS}

BOFF, C. Como trabalhar com o povo: metodologia do trabalho popular. Petrópolis: Vozes, 1986.

\section{BOFF, L. Teologia do cativeiro e da libertação.}

Petrópolis, RJ: Vozes, 1980.

BOFF, L.; BOFF, C. Da libertação: o sentido teológico das libertações sócio-históricas. Petrópolis: Vozes, 1979.

Como fazer teologia da libertação. 8. ed.

Petrópolis, RJ: Vozes, 2001.

FREIRE, P. Extensão ou comunicação? Rio de Janeiro: Paz e Terra, 1971.

. Conscientização: teoria e prática da libertação.

São Paulo: Moraes, 1980.

Pedagogia do oprimido. 17. ed. Rio de

Janeiro: Paz e Terra, 1987.

Pedagogia da autonomia: saberes necessários

à prática educativa. São Paulo: Paz e Terra, 2007.

GUTIÉRREZ, G. Teologia da libertação: perspectivas.

São Paulo: Edições Loyola, 2000.

BRASIL. Presidência da República. Secretaria de Assuntos Estratégicos. Brasil 2022: Trabalhos Preparatórios. Brasília, DF: Presidência da República, Secretaria de Assuntos Estratégicos (SAE), 2010.

LÖWY, M. Marxismo e teologia da libertação. São

Paulo: Cortez; Autores Associados, 1938.

RIBEIRO, R. M. C. R. A Extensão Universitária como indicativo de responsabilidade social. Revista Diálogos: pesquisa em extensão universitária, Brasília, DF. v. 15, n. 1, jul., 2011. 
SERRANO, R. M. S. M. Conceitos de extensão

universitária: um diálogo com Paulo Freire. Dezembro,

2011. Disponível em: <http://www.prac.ufpb.br/copac/ extelar/atividades/discussao/artigos/conceitos_de extensao_universitaria.pdf $>$. Acesso em: $1^{\circ}$ dez. 2011.

TENÓRIO, F. G. A trajetória do Programa de Estudos em Gestão Social (PEGS). RAP, Rio de Janeiro, v. 40, n. 6, p. 1.145-1.162, 2006.

Tem razão a administração? Ensaios de

teoria organizacional. 3. ed. Ijuí: Editora Unijuí, 2008a.

\section{Um espectro ronda o terceiro setor: o}

espectro do mercado. Ensaios de gestão social. 3. ed. rev. e ampl. Ijuí: Editora Unijui, 2008b.

Gestão Comunitária: uma abordagem prática. Rio de Janeiro: Editora FGV, 2008c.

Gestão social: uma réplica. Revista ADM.

\section{Made: Revista do Mestrado em Administração e}

Desenvolvimento Empresarial. Rio de Janeiro, ano 9, v. 13, n. 2, p. 1-4, maiolago. 2009.

Tem Razão a Gestão Social? Texto

apresentado no II SEMINÁRIO DE GESTÃO

SOCIAL E DESENVOLVIMENTO. PROJETO PRÓ-

ADMINISTRAÇÃO/CAPES. Florianópolis, SC, 22 e 23 de novembro, 2012. Anais... Florianópolis, CAPES, 2012.

THIOllent, M. J. M. Metodologia da Pesquisa-Ação.

8. ed. São Paulo: Cortez, 1998.

Construção do conhecimento e metodologia da extensão. I CBEU - CONGRESSO BRASILEIRO DE EXTENSÃO UNIVERSITÁRIA. João Pessoa, Paraíba.

Dezembro de 2002. Anais... João Pessoa, 2012.

\section{NOTAS}

${ }^{1}$ O Plano Brasil 2022 tem como propósito tecer estratégias para o futuro do País, fixando metas para o ano de 2022, quando o Brasil comemora o bicentenário de sua independência. A sua elaboração envolveu grupos de trabalho formados por técnicos da Secretaria de Assuntos Estratégicos (SAE) da Presidência da República, representantes de todos os Ministérios, da Casa Civil e do Instituto de Pesquisa Econômica Aplicada (IPEA). Disponível em: <http://www.sae.gov.br/site/wp-content/uploads/ Brasil_2022_volume2.pdf $>$. Acesso em: $1^{\circ}$ abr. 2012. 